\title{
GPS detection of total electron content variations over Indonesia and Thailand following the 26 December 2004 earthquake
}

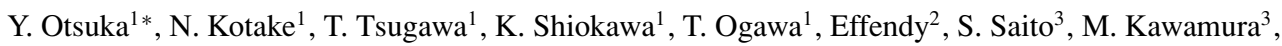 \\ T. Maruyama ${ }^{3}$, N. Hemmakorn ${ }^{4}$, and T. Komolmis ${ }^{5}$ \\ ${ }^{1}$ Solar-Terrestrial Environment Laboratory, Nagoya University, Japan \\ ${ }^{2}$ National Institute for Aeronautics and Space, Bandung, Indonesia \\ ${ }^{3}$ National Institute of Information and Communications Technology, Tokyo, Japan \\ ${ }^{4}$ King Mongkut's Institute of Technology Ladkrabang, Bangkok, Thailand \\ ${ }^{5}$ Chiang Mai University, Chiang Mai, Thailand
}

(Received May 27, 2005; Revised December 3, 2005; Accepted December 16, 2005; Online published February 17, 2006)

\begin{abstract}
We report the response of the ionosphere to the large earthquake that occurred in West Sumatra, Indonesia, at 0058 UT on December 26, 2004. We have analyzed Global Positioning System (GPS) data obtained at two sites in Sumatra and at three sites in Thailand to investigate total electron content (TEC) variations. Between 14 and 40 min after the earthquake, TEC enhancements of 1.6-6.9 TEC units (TECU) were observed at subionospheric points located 360-2000 km north of the epicenter. From the time delays of the observed TEC enhancements, we find that the TEC enhancements propagated northward from the epicenter. The time delays between the earthquake and rapid increases in TEC, which occurred near the epicenter, are consistent with the idea that acoustic waves generated by the earthquake propagated into the ionosphere at the speed of sound to cause the TEC variations. A small TEC enhancement of 0.6 TECU was observed south of the epicenter, while no TEC enhancements were seen east of the epicenter. From a model calculation, we find that this directivity of the TEC variations with respect to the azimuth from the epicenter could be caused partially by the directivity in the response of the electron density variation to the acoustic waves in the neutral atmosphere.
\end{abstract}

Key words: Ionosphere, earthquake, GPS, total electron content, acoustic wave.

\section{Introduction}

Atmospheric and ionospheric disturbances following impulsive forcing on the ground, such as earthquakes, volcanic eruptions, and powerful explosions, have been observed with various techniques (e.g., Ogawa et al., 1982; Blanc, 1985; Kanamori et al., 1994; Igarashi et al., 1994). These impulsive sources generate vertical displacement of the atmosphere at the earth's surface, exciting atmospheric infrasonic acoustic waves. Since atmospheric density decreases nearly exponentially with altitude, energy conservation requires the amplitude of the waves to increase as they propagate upward. The amplitude at ground level can be amplified by $\sim 10^{5}-10^{6}$ at the ionospheric altitude, where the atmospheric waves cause a perturbation in the electron density through ion-neutral collisions. Ionospheric disturbances have been detected by HF-Doppler sounding, which is very sensitive to rapid changes in electron density in the bottomside ionosphere (e.g., Tanaka et al., 1984). The vertical oscillations of the bottomside ionosphere measured by HF-Doppler sounders have been reproduced in model calculations which simulate acoustic gravity waves propagating from the ground to the ionosphere (Artru et al., 2004).

\footnotetext{
*Present address: 3-13 Honohara, Toyokawa, Aichi 442-8507, Japan
}

Copyright (c) The Society of Geomagnetism and Earth, Planetary and Space Sciences (SGEPSS); The Seismological Society of Japan; The Volcanological Society of Japan; The Geodetic Society of Japan; The Japanese Society for Planetary Sciences; TERRAPUB
In recent years, Global Positioning System (GPS) data have been used to measure total electron content (TEC) variations related to earthquakes (Calais and Minster, 1995; Afraimovich et al., 2001). Using TEC data obtained from a dense GPS network in Southern California, Calais and Minster (1995) have shown an ionospheric response to the 1994 Northridge, California earthquake. Heki and Ping (2005) have used a dense GPS network in Japan to produce two-dimensional maps of TEC variations after thrust earthquakes off the Pacific coast of Japan.

In the earth's atmosphere, there are various kinds of atmospheric waves with different spatial and temporal scales. Many of the waves are thought to be generated in the lower atmosphere and propagate upward to the middle and upper atmosphere. Furthermore, some of the waves are considered to reach the ionosphere, where they cause perturbations in the ionospheric electron density (e.g., Hines, 1960). However, it is not clearly understood how the waves propagate up to the ionosphere. Studying atmospheric and ionospheric responses to known wave sources, such as earthquakes and volcanic eruptions, would lead to a better knowledge of wave propagation mechanisms. For this reason, we investigated ionospheric perturbations which could be produced by a large earthquake that occurred near Sumatra Island in Indonesia on December 26, 2004. 


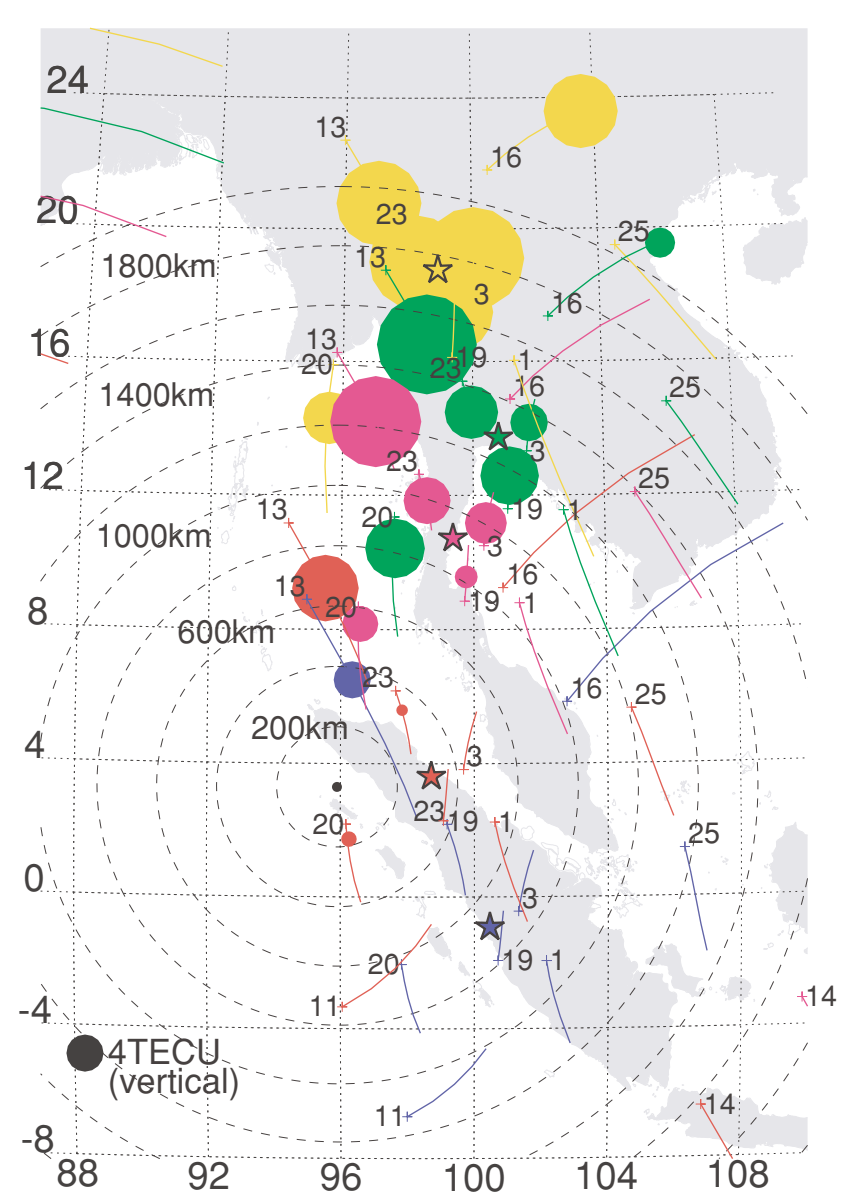

Fig. 1. Map showing GPS observation sites at Padang (blue star), Sampali (red star), Chumphon (magenta star), Bangkok (green star), and Chiang Mai (orange star). Solid lines show trajectories of subionospheric points at an altitude of $300 \mathrm{~km}$ for ray paths between GPS satellites (PRN13, $23,20,21,03,19,01,25$ and 16) and receivers at the five sites between 0100 and 0200 UT on December 26, 2004. Plus (+) indicates the location of the subionospheric points at $0100 \mathrm{UT}$. The diameter of the solid circles on the trajectories indicates the amplitude of TEC enhancement, which is converted to TEC in the vertical direction. The black circle shows the epicenter of the Sumatra-Andaman earthquake. Horizontal distance from the epicenter is shown by dotted concentric circles.

\section{Observations and Results}

On December 26, 2004, a large earthquake with a moment magnitude $\left(M_{w}\right)$ of 9.0 occurred near Sumatra Island in Indonesia (Park et al., 2005). The Indonesian subduction zone near the northern end of Sumatra began to rupture at $0058 \mathrm{UT}$. The rupture continued for approximately 7 min, extending northwestward along the Sunda Trench for roughly $1200 \mathrm{~km}$ to the Andaman Islands. In this study, we assume that the epicenter is located at $\left(3.3^{\circ} \mathrm{N}, 95.9^{\circ} \mathrm{E}\right)$ and that acoustic waves were generated at the epicenter (the location of the epicenter is shown in Fig. 1).

The stars in Fig. 1 denote the locations of five dualfrequency GPS receivers whose data are used in the present study. The receiver at Padang $\left(0.9^{\circ} \mathrm{S}, 100.5^{\circ} \mathrm{E}\right)$ has been operated by the Solar-Terrestrial Environment Laboratory, Nagoya University, since October 2002. Data from the receiver at Sampali $\left(3.6^{\circ} \mathrm{N}, 98.7^{\circ} \mathrm{E}\right)$ are taken from the Scripps Orbit and Permanent Array Center (SOPAC). The (a)

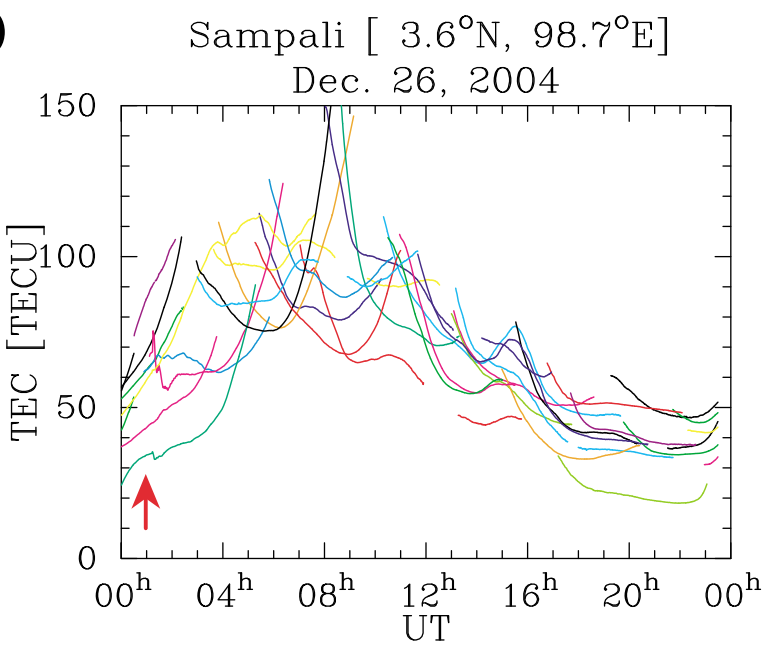

(b)
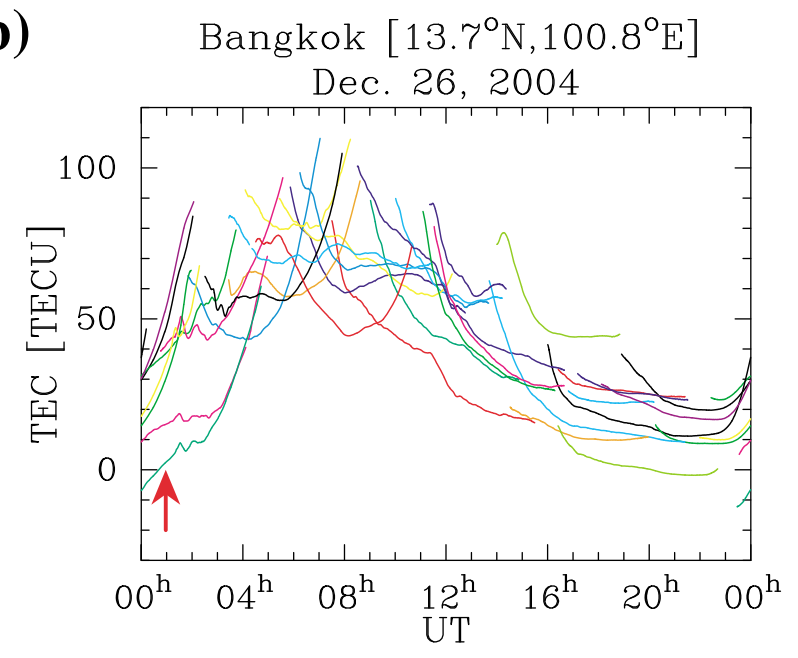

(c) Chiang Mai $\left[18.8^{\circ} \mathrm{N}, 98.9^{\circ} \mathrm{E}\right]$

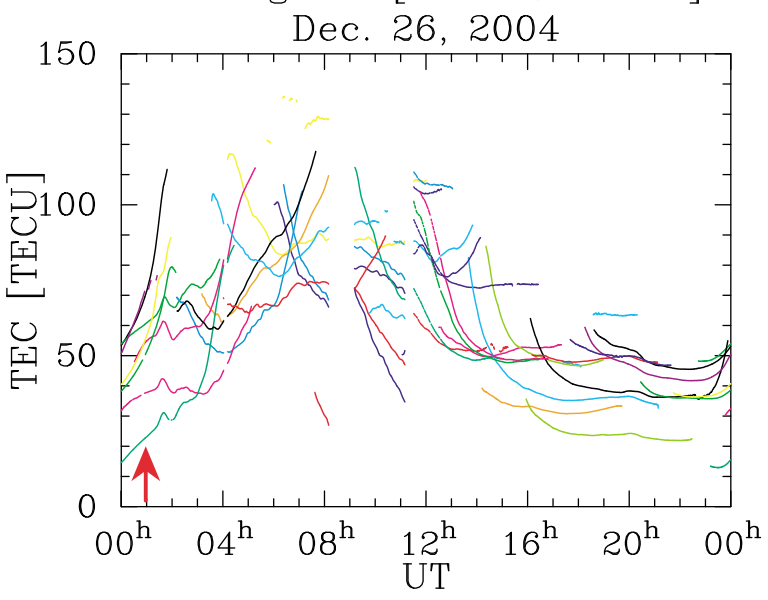

Fig. 2. Temporal variation of the slant TEC observed at (a) Sampali, (b) Bangkok, and (c) Chiang Mai on December 26, 2004. Red arrow indicates time of the earthquake (0058 UT). It should be noted that TEC values include biases inherent in satellite and receiver hardwares.

other three receivers were installed at Chumphon $\left(10.7^{\circ} \mathrm{N}\right.$, $\left.99.4^{\circ} \mathrm{E}\right)$, Bangkok $\left(13.7^{\circ} \mathrm{N}, 100.8^{\circ} \mathrm{E}\right)$, and Chiang Mai $\left(18.8^{\circ} \mathrm{N}, 98.9^{\circ} \mathrm{E}\right)$ in Thailand by the National Institute of Information and Communications Technology (NICT), King Mongkut's Institute of Technology Ladkrabang, and Chiang Mai University. These five receivers provide carrier 

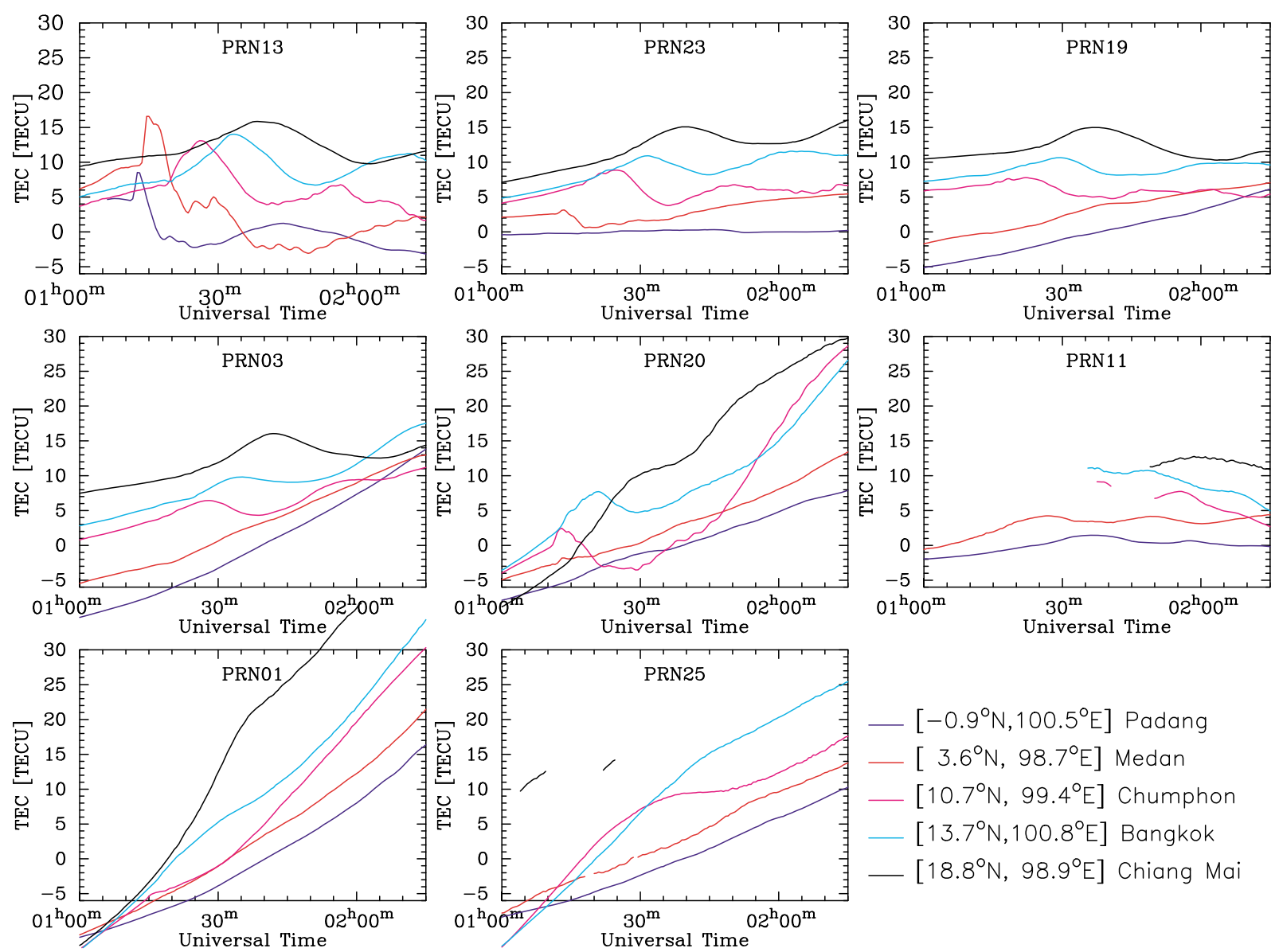

Fig. 3. Temporal variation of the slant TEC along ray paths between GPS satellites (PRN13, 23, 20, 21, 03, 19, 01, 25) and receivers at Padang, Sampali, Chumphon, Bangkok, and Chiang Mai at 0100-0215 UT on December 26, 2004.

phase delays and group delays (P-code pseudoranges) of dual frequency $(1.57542$ and $1.22760 \mathrm{GHz})$ GPS signals every 1 or 30 seconds. Total electron content (TEC) along a ray path from a GPS satellite to a receiver is precisely obtained from the carrier phase delays, although a level of the TEC is unknown because of an unknown initialization constant in phase measurements. The ambiguity in phase measurements is removed by using the measured pseudoranges. TEC values obtained using that procedure still contain biases inherent in satellite and receiver hardware. To get absolute TEC, these biases must be removed. The absolute value, however, is not used in this study, because we focus on the short-scale perturbations of TEC.

Figure 2 shows temporal variations of the slant TEC observed at Sampali, Bangkok, and Chiang Mai on December 26, 2004. Each curve corresponds to a time sequence of TEC along a ray path between a satellite and a receiver. It should be noted that the TEC values contain biases inherent in satellite and receiver hardwares. Red arrow in each panel indicates time of the earthquake (0058 UT). After the earthquake, TEC perturbations with duration of several ten minute were observed at several ray paths between satellites and receivers. Figure 3 shows temporal variations of the slant TEC observed by the five GPS receivers at Padang, Sampali, Chumphon, Bangkok, and Chiang Mai between 0100 and 0215 UT on December 26, 2004. During this period, TEC data were simultaneously obtained from nine satellites (PRN01, 03, 11, 13, 16, 19, 20, 23, 25) at the five GPS sites. A clear increase in TEC was observed along the ray paths from the PRN13 satellite to the five sites. The increase was first observed at Padang, and then successively at Sampali, Chumphon, Bangkok, and Chiang Mai. The trajectories of the subionospheric points at an altitude of 300 $\mathrm{km}$ are shown in Fig. 1. The TEC perturbations occurred at the subionospheric points at horizontal distances of 380 , $670,1270,1570$, and $12030 \mathrm{~km}$ away from the epicenter.

The diameter of the solid circles in Fig. 1 indicates the amplitude of the TEC enhancement, which is converted to TEC in the vertical direction from the slant TEC using a slant factor. The slant factor $S$ is defined by $S=\tau_{1} / \tau_{0}$, where $\tau_{1}$ is the length of the ray path between 200 and 450 $\mathrm{km}$ altitudes, and $\tau_{0}$ is the ionospheric thickness of $250 \mathrm{~km}$ for the zenith path (Saito et al., 1998). As described above, large TEC enhancements were observed to the north of the epicenter. To the south of the epicenter, on the contrary, TEC was slightly enhanced by 0.6 TECU at the ray path from the PRN20 satellite to the receiver at Sampali, while no enhancement was seen further south and east of the epicenter. The observational results show the directivity of the TEC variations with respect to the azimuth from the epicenter.

TEC enhancements less than $\sim 20$ min after the earthquake are characterized by a rapid increase with a time scale of 1-2 min and a relatively slow decrease. These TEC en- 


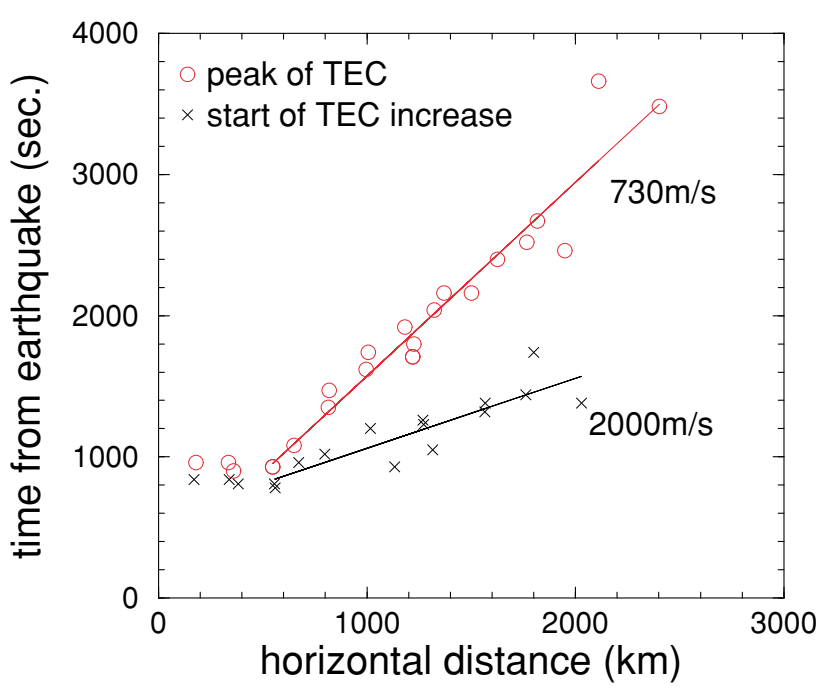

Fig. 4. Time delay from the earthquake to (black cross) start of the TEC increase and (red circle) peak of the TEC variations as a function of the horizontal distance of the subionospheric points from the epicenter. Black and red lines represent linear regression of the data shown by black crosses and red circles, respectively. Data less than $500 \mathrm{~km}$ from the epicenter are excluded for this linear regression.

hancements are located within a horizontal distance of 800 $\mathrm{km}$ from the epicenter (Fig. 1). On the other hand, TEC variations more than $\sim 20$ min after the earthquake are continuously sinusoidal and are located more than $\sim 800 \mathrm{~km}$ north of the epicenter. The time scale of these TEC variations tends to be longer, from 10 to $30 \mathrm{~min}$, as the waves propagate northward from the epicenter.

Figure 4 shows time delays between the earthquake occurrence (0058 UT) and the start of the TEC increase (black crosses) as a function of the horizontal distance of the subionospheric points from the epicenter. Time delays between the earthquake occurrence and the peak of the TEC variations are shown by red circles in the figure. The black and red lines represent linear regression of the data shown by the black crosses and red circles, respectively. The data less than $500 \mathrm{~km}$ from the epicenter are excluded from this linear regression. The start and peak of the TEC enhancements are found to propagate at velocities of 2000 and 770 $\mathrm{m} / \mathrm{s}$, respectively.

\section{Discussion}

Rapid TEC increases were observed near the epicenter. Since the time scale of these TEC increases was 1-2 min, we speculate that they are caused by acoustic waves, as in the previous observations reported by Calais and Minster (1995), Afraimovich et al. (2001), and Heki and Ping (2005). We assume that the acoustic waves in the atmosphere were launched from the epicenter on the sea surface due to the coupling between the sea surface and the atmosphere, and that they propagated upward to the ionosphere. Ray paths of the acoustic waves were calculated using the altitude profile of sound velocity (Fig. 5). The sound velocity is proportional to the square root of the neutral temperature. In this calculation, the neutral temperature is taken from the NRLMSISE-00 model, which is an empirical model of the neutral atmosphere based on observational

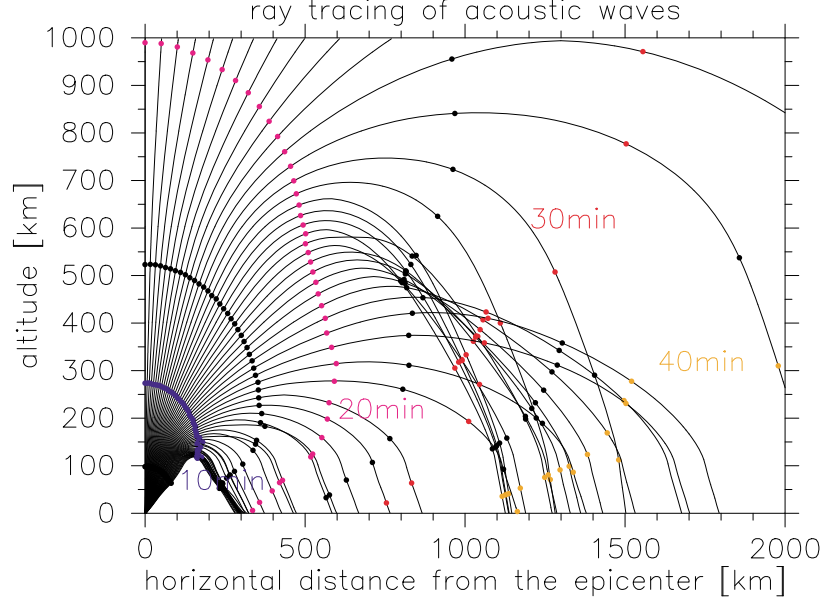

Fig. 5. Ray tracing of acoustic waves originating from a point source on the surface of the Earth. The waves launched with elevation angles of $30^{\circ}-90^{\circ}$ are shown at $1^{\circ}$ intervals. Locations of the waves $5-40 \mathrm{~min}$ after the earthquake are shown in the figure.

results (Picone et al., 2002). Since the neutral temperature rapidly increases with altitude above the mesopause $(\sim 90$ $\mathrm{km}$ altitude), the sound velocity also rapidly increases with altitude. Because of this dependence of the sound velocity on altitude, only the waves launched with elevation angles of $60^{\circ}-90^{\circ}$ at the ground can propagate up to the altitude of the ionosphere. At horizontal distance of $360 \mathrm{~km}$ from the epicenter, the acoustic waves reach ionospheric altitudes of $\sim 300 \mathrm{~km} 15 \mathrm{~min}$ after the wave launching. This time delay is consistent with the observational results shown in the present study.

However, the calculated results shown in Fig. 5 represent that it takes more than 30 min for the acoustic waves to reach the location of $1200 \mathrm{~km}$ from the epicenter, while TEC enhancements were observed to start 20 min after the earthquake. This discrepancy between observed and calculated results could be caused by the assumption that the acoustic waves were generated from a point source at the epicenter. Lay et al. (2005) reported that the seismic rupture front propagated to about $1200 \mathrm{~km}$ north of the epicenter with a velocity of about $2.0 \sim 3.0 \mathrm{~km} / \mathrm{s}$. This result indicates that acoustic waves would be excited sequentially at multiple points, and that the wave source would propagate northward at the almost same velocity as the rupture. Since the velocity of the rapture is larger than the sound velocity, the acoustic waves excited during the rupture propagation reaches ionospheric altitudes at the north of the epicenter earlier than the acoustic waves excited at the epicenter. Therefore, the initial ionospheric response would propagate northward at the same velocity as the rupture. Actually, our observational results showed the initial TEC response propagated at $2 \mathrm{~km} / \mathrm{s}$.

The time scale of the TEC variations tended to be longer, from 10 to $30 \mathrm{~min}$, as the wave propagated northward from the epicenter. This tendency is consistent with that reported by Heki and Ping (2005). In the present event, more than $\sim 800 \mathrm{~km}$ north of the epicenter, sinusoidal variations of TEC with periods of 20-30 min were observed more than 20 min after the earthquake occurred. Acoustic waves 
with periods longer than the acoustic cutoff period (approximately $11 \mathrm{~min}$ in the ionospheric $F$ region) are damped. Therefore, the observed sinusoidal TEC variations with apparent periods longer than the acoustic cutoff period would be caused by overlapping acoustic waves generated at different locations during the rupture propagation. Another possibility is that gravity waves generated by the acoustic waves propagated northward, causing the observed TEC variations.

Here, we focus our discussion on TEC variations near (less than $\sim 800 \mathrm{~km}$ from) the epicenter, which are expected to be caused by acoustic waves excited near the epicenter. Due to the acoustic waves, the neutral particles oscillate parallel to the wave propagation direction. In the $F$ region, the neutral particles move ions along the geomagnetic field lines through the neutral-ion collisions. The ion motion across the magnetic field line is restricted because the ion gyro-frequency is much higher than ion-neutral collision frequency. This directivity of the ion mobility causes directivity in the response of the electron density variations to the neutral motion. Hooke (1968) has shown that the velocity of the ion motion along the geomagnetic field line is the same as that of neutral motion caused by gravity waves. This idea is also applicable to the case of acoustic waves, where the neutral wind velocity (u) is parallel to the wave vector (k), whereas $\mathbf{u}$ is perpendicular to $\mathbf{k}$ in the case of gravity waves. In the $F$ region, the electron density perturbation $N_{e}^{\prime}$, which is caused by the oscillating neutral wind velocity $\mathbf{u}$, is given by

$$
N_{e}^{\prime}=i \frac{u_{b}}{\omega}\left[\frac{\partial N_{e}}{\partial z} \sin I-i k_{b} N_{e}\right]
$$

where $i=\sqrt{-1}, \omega$ is the angular frequency of the acoustic wave, $u_{b}$ and $k_{b}$ are the projection of $\mathbf{u}$ and $\mathbf{k}$ in the direction of the geomagnetic field, respectively, $I$ is the dip angle of the geomagnetic inclination, and $N_{e}$ is the ambient electron density. The perturbation quantities are assumed to be described by plane waves of the form $N_{e}^{\prime}, \mathbf{u} \propto$ $\exp \{i(\omega t-\mathbf{k} \cdot \mathbf{x})\}$. The first and second terms of Eq. (1) indicate the electron density perturbations caused by vertical motions of the $F$ layer plasma and by convergence and divergence of ions along the field line, respectively. In general, $\omega$ is a real number and $\mathbf{k}$ is a vector of complex numbers. When $\mathbf{k}$ has an imaginary part, amplitude of the electron density perturbation grows or decays with time. In this study, we assume that the amplitude of the perturbations does not change with time (k has only real numbers).

Figure 6 shows the result of a model calculation simulating electron density perturbation in the altitude from 200 to $600 \mathrm{~km}$ at the subionospheric point for the ray path between the PRN13 satellite and Padang $\left(6.5^{\circ} \mathrm{N}, 96.3^{\circ} \mathrm{E}\right), 360 \mathrm{~km}$ north (azimuth of $8^{\circ}$ from the north) of the epicenter. The inclination $I$ at this location is $-4.0^{\circ}$ (IGRF-2000 model; Olsen et al., 2000). The background electron density profile is taken from the IRI model. In this calculation, $f_{o} F_{2}$ is set at $9.0 \mathrm{MHz}$, which corresponds to a peak electron density of $10^{12} \mathrm{~m}^{-3}$. This $f_{o} F_{2}$ was observed by an ionosonde at Kototabang $\left(0.20^{\circ} \mathrm{S}, 100.32^{\circ} \mathrm{E}\right)$, West Sumatra, which was operated by NICT. From the ray tracing calculations for acoustic waves (Fig. 5), the acoustic wave is found to prop-

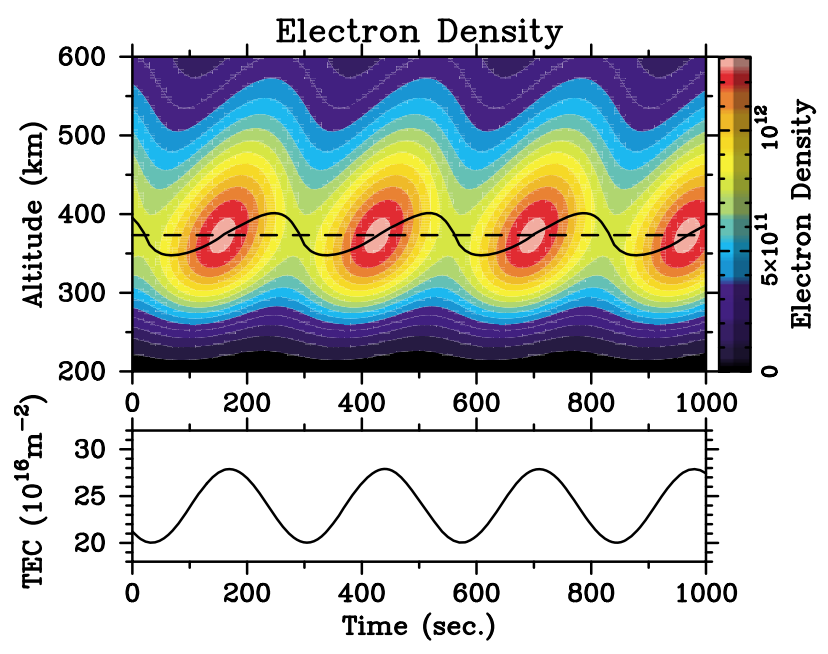

Fig. 6. Model calculation of the electron density perturbations caused by an acoustic wave at $\left(6.5^{\circ} \mathrm{N}, 96.3^{\circ} \mathrm{E}\right)$, where the geomagnetic inclination $I$ is $-4.0^{\circ}$. The basic parameters of the acoustic wave are $T=4.5 \mathrm{~min}$, $C=780 \mathrm{~m} / \mathrm{s}, \alpha=19^{\circ}$, and $U=210 \mathrm{~m} / \mathrm{s}$, where $T$ is the wave period, $C$ is the speed of sound, $\alpha$ is the elevation angle of the propagation direction, and $U$ is the amplitude of the neutral wind velocity. The color scale, black solid line, and black dashed line in the top panel indicate the electron density, peak altitude of the electron density, and original peak altitude without the perturbations, respectively. The bottom panel indicates TEC obtained from integration from $200 \mathrm{~km}$ to $600 \mathrm{~km}$ altitudes.

agate at $780 \mathrm{~m} / \mathrm{s}$ with an elevation angle of $19^{\circ}$ at a $300 \mathrm{~km}$ altitude over the above location. In the model calculation, these values are assumed to be constant with altitude. A wave period and amplitude of the neutral wind velocity $(U)$ are $4.5 \mathrm{~min}$ and $210 \mathrm{~m} / \mathrm{s}$, respectively, for all altitudes. This amplitude gives an electron density perturbation of $\sim 25 \%$ from the background electron density, as shown in the top panel. The electron density is integrated from $200 \mathrm{~km}$ to $600 \mathrm{~km}$ altitude to obtain the vertical TEC (bottom panel). The amplitude of the TEC variation is $4.0 \mathrm{TECU}$, which is comparable to the TEC observed along the ray path between the PRN13 satellite and Padang. This result indicates that the acoustic waves generated by the earthquake propagated into the ionosphere and that they had neutral wind variation with an amplitude of $\sim 210 \mathrm{~m} / \mathrm{s}$ in the $F$ region (around 300 $\mathrm{km}$ altitude). Amplitude of neutral wind velocity variations due to the acoustic waves at the earth's surface could be of the order of centimeter per second, but it could be amplified to $\sim 210 \mathrm{~m} / \mathrm{s}$ in the $F$ region because it increases with altitude to maintain kinetic energy of the acoustic waves. The amplitude of the acoustic wave in this model calculation is larger than that of gravity waves which would be responsible for medium-scale traveling ionospheric disturbances (Fukao et al., 1993; Kirchengast, 1996). These previous studies suggested that the gravity waves have neutral wind velocity with an amplitude of $\sim 10 \mathrm{~m} / \mathrm{s}$.

To investigate the mechanism that caused the azimuthal directivity of TEC variations shown in Fig. 1, similar calculations were conducted with different parameters depending on the location (propagation direction of the acoustic waves and inclination of the geomagnetic field). The other parameters are the same as in the above calculation. A wave period of $4.5 \mathrm{~min}$ and $U=210 \mathrm{~m} / \mathrm{s}$ are adopted. Figure 7 


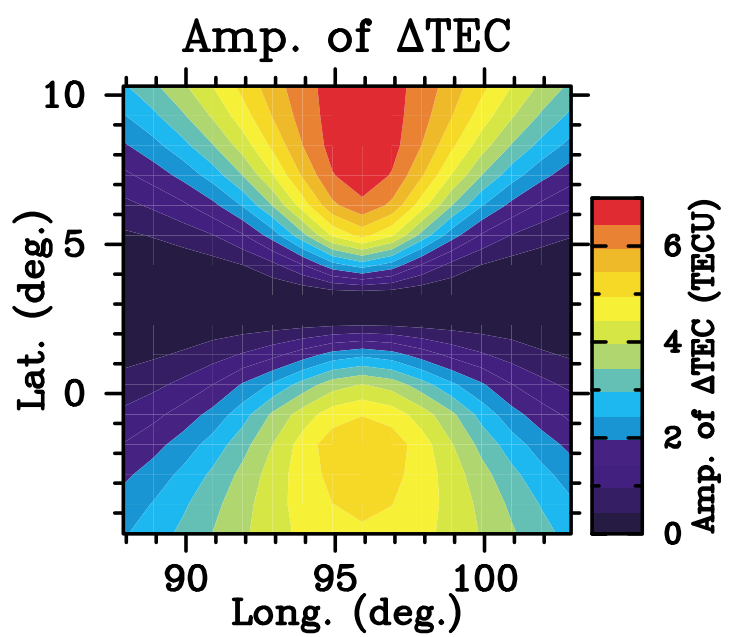

Fig. 7. Response of TEC to an acoustic wave in the area of $4.2^{\circ} \mathrm{S}-10.8^{\circ} \mathrm{N}$ latitude and $88.4^{\circ}-103.4^{\circ} \mathrm{E}$ longitude. The inclination of the geomagnetic field is taken from the IGRF-2000 model. We assume that the acoustic wave with $T=4.5 \mathrm{~min}$ and $U=210 \mathrm{~m} / \mathrm{s}$ propagates isotropically from the epicenter without attenuation.

shows a map of the TEC variation amplitude in geographical coordinates in the area of $4.2^{\circ} \mathrm{S}-10.8^{\circ} \mathrm{N}$ latitude and $88.4^{\circ}-103.4^{\circ} \mathrm{E}$ longitude. In this area, the inclination of the geomagnetic field varies from $-28.6^{\circ}\left(4.2^{\circ} \mathrm{S}\right)$ to $6.5^{\circ}$ $\left(10.8^{\circ} \mathrm{N}\right)$. The geomagnetic equator $\left(I=0^{\circ}\right)$ is about $8^{\circ} \mathrm{N}$ in this longitudinal sector. Acoustic waves are assumed to propagate isotropically from the epicenter without attenuation.

The following two features seen in Fig. 7 are consistent with the observational results. (1) The amplitude of the TEC variations for the acoustic waves propagating in the meridional direction is larger than that for the acoustic waves propagating in the zonal direction. (2) The amplitude of the TEC variations is larger north of the epicenter than south of it. These features are explained by the response of the electron density to neutral motion caused by acoustic waves. Large $N_{e}^{\prime}$ can be produced under the condition that $u_{b}$ and/or $k_{b}$ are large, as shown in Eq. (1). This condition is satisfied when the acoustic wave propagates parallel to the geomagnetic field, because $u_{b}$ is parallel to $k_{b}$. Therefore, the amplitude of the TEC variation is mainly controlled by the angle between the directions of wave propagation and the geomagnetic field. A large TEC variation would occur when the acoustic wave propagates in the meridional direction along the geomagnetic field. As for north-south asymmetry of the TEC variations, $u_{b}$ and $k_{b}$ of the northward (geomagnetically equatorward) propagating waves are larger than those of the southward (geomagnetically poleward) propagating waves, as shown schematically in Fig. 8. North of the epicenter, the geomagnetic field line is nearly horizontal (the inclination is zero around $8^{\circ} \mathrm{N}$ ). Since $\mathbf{k}$ also becomes horizontal as the wave propagates, $\mathbf{k}$ and $\mathbf{u}$ are nearly parallel, and then $k_{b}$ and $u_{b}$ are large. Near the epicenter, the wave propagates with a relatively large elevation angle. This causes small $k_{b}$ and $u_{b}$ and then small TEC variations,

Calais and Minster (1995) have shown directivity of the TEC variations with respect to the azimuth from the epi-
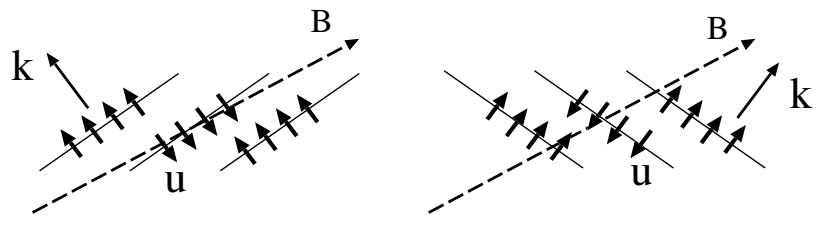

$\underset{\text { southward }}{\stackrel{\text { epicenter }}{\longrightarrow} \text { northward }}$

Fig. 8. Schematic diagram of southward (geomagnetically poleward) and northward (geomagnetically equatorward) propagating acoustic waves. The geomagnetic field line is indicated by the dashed arrows. When the wave propagates northward, both $u \cdot B$ and $k \cdot B$ are large, so that the wave produces a significantly large response in electron density.

center after the January 17, 1994, Northridge earthquake. A smaller amplitude of the TEC variations was observed southwest of the epicenter and a larger amplitude northeast of that. Calais and Minster (1995) described that this azimuthal directivity may be caused by the land/ocean distribution in the Los Angeles area. Using a dense GPS network in Japan, Heki and Ping (2005) showed two-dimensional maps of TEC variations after thrust earthquakes off the Pacific coast of Japan. They reported that the amplitude of the TEC variations has strong directivity. Southward (equatorward) propagating waves of the TEC variations had a larger amplitude than northward (poleward) propagating waves. They suggested that this north-south asymmetry in the amplitude of the TEC variations could be caused by the directivity in the response of the electron density variation to the acoustic waves in the neutral atmosphere. While these results were obtained at midlatitudes, the present study shows the TEC variations associated with the large earthquake in the equatorial region, where the geomagnetic field lines are nearly horizontal. The present results support the idea that the directivity of the TEC variations with respect to the azimuth from the epicenter could be caused by the directivity in the response of the electron density variation to the acoustic waves in the neutral atmosphere.

As shown in Fig. 7, near (less than $\sim 800 \mathrm{~km}$ from) the epicenter, directivity of TEC perturbation amplitude with respect to the azimuth was reproduced in the above model calculation. However, TEC perturbations more than $\sim 800$ $\mathrm{km}$ far from the epicenter are not reproduced. This is probably because the assumption of a point source of the acoustic wave is not valid. As described above, acoustic waves would be generated at multiple points which moved northward from the epicenter. The wave sources could be extended $\sim 1200 \mathrm{~km}$ north of the epicenter. This wave source distribution could be responsible for the northward extension of the region where the TEC enhancements were observed. Consequently, superimposition of acoustic waves generated sequentially at different locations need to be considered to reproduce the observed TEC variations.

The electron density perturbation has a structure with a wavefront same as the acoustic waves propagating in the $F$ region, as shown in Fig. 6. Amplitude of the observed TEC perturbation could depend on configuration of the electron density structure and satellite-receiver ray path. In the case 
that the ray path is parallel to the wavefront, apparent amplitude of TEC perturbations is large. On the other hand, in the case that the ray path crosses the wavefront, apparent amplitude of TEC perturbation is small because TEC value is an average over different phases of the wave structure. This effect on the apparent amplitude of TEC perturbation is not considered in this study, and a slant factor is used to convert slant TEC to vertical TEC. For further detail studies, configuration of the satellite-receiver ray path and wavefronts of the TEC perturbations needs to be considered.

\section{Summary}

The Sumatra-Andaman earthquake occurred at 00:58 UT on December 26, 2004. To investigate the effects of the earthquake on the ionosphere, we have analyzed Global Positioning System (GPS) data obtained at Padang and Sampali in Indonesia and at Chumphon, Bangkok, and Chiang Mai in Thailand. The observational results showed directivity of the TEC variations with respect to the azimuth from the epicenter. Large TEC enhancements (1.6-6.9 TECU) were observed north of the epicenter. South of the epicenter, on the contrary, TEC was only slightly enhanced, by 0.6 TECU, and TEC enhancement was not seen east of the epicenter. TEC enhancements less than $\sim 20 \mathrm{~min}$ after the earthquake (less than $\sim 800 \mathrm{~km}$ from the epicenter) were accompanied by rapid increases, while TEC variations after that had a sinusoidal time dependence. Near (less than $\sim 800 \mathrm{~km}$ from) the epicenter, the time delay from the earthquake to the rapid increases in TEC is consistent with the idea that acoustic waves generated by the earthquake propagated into the ionosphere at the speed of sound, causing the TEC variations. A model calculation showed that the observed directivity of the TEC variations near the epicenter with respect to the azimuth from the epicenter could be caused by directivity in the response of the electron density variation to the neutral motion of acoustic waves in oblique geomagnetic field lines. Furthermore, the model calculation demonstrated that the amplitude of the neutral wind velocity caused by the acoustic wave is $210 \mathrm{~m} / \mathrm{s}$ in the $F$ region.

The start and peak of the TEC enhancements propagated at velocities of 2000 and $770 \mathrm{~m} / \mathrm{s}$, respectively. The time scale of the TEC variations tended to be longer, from 10 to $30 \mathrm{~min}$, as the wave propagated northward from the epicenter. Since the time scale exceeds the acoustic cutoff period in the thermosphere, the TEC variations observed more than $\sim 800 \mathrm{~km}$ north of the epicenter cannot be explained in terms of acoustic waves generated from a point source at the epicenter. It would be necessary to consider acoustic waves generated at the multiple point sources which move sequentially from south to north.

Acknowledgments. GPS data obtained at Sampali were provided by the Scripps Orbit and Permanent Array Center (SOPAC). A GPS receiver at Padang has been operated in collaboration with the University of Andalas. This work is supported by a Grant-in-Aid for Scientific Research on Priority Area (764) and the 21st Century COE Program (Dynamics of the Sun-Earth-Life Interactive System, No. G-4) of the Ministry of Education, Culture, Sports, Science and Technology of Japan.

\section{References}

Afraimovich, E. L., N. P. Perevalova, A. V. Plotnikov, and A. M. Uralov, The shock-acoustic waves generated by earthquakes, Ann. Geophys., 3, 673-686, 2001.

Artru, J., T. Farges, and P. Lognonné, Acoustic waves generated from seismic surface waves: propagation properties determined from Doppler sounding observations and normal-mode modeling, Geophys. J. Int., 158, 1067-1077, 2004.

Blanc, E., Observations in the upper atmosphere of infrasonic waves from natural or artificial sources: A summary, Ann. Geophys., 19, 395-409, 1985.

Calais, E. and J. B. Minster, GPS detection of ionospheric perturbations following the January 17, 1994, Northridge earthquake, Geophys. Res. Lett., 22, 1045-1048, 1995.

Fukao, S., Y. Yamamoto, W. L. Oliver, T. Takami, M. D. Yamanaka, M. Yamamoto, T. Nakamura, and T. Tsuda, Middle and upper atmosphere radar observations of ionospheric horizontal gradients produced by gravity waves, J. Geophys. Res., 98, 9443-9451, 1993.

Heki, K. and J. Ping, Directivity and apparent velocity of the coseismic traveling ionospheric disturbances observed with a dense GPS array, Earth Planet. Sci. Lett., 236, 845-855, 2005.

Hines, C. O., Internal atmospheric gravity waves at ionospheric heights, Can. J. Phys., 38, 1441-1481, 1960.

Hooke, W. H., Ionospheric irregularities produced by internal atmospheric gravity waves, J. Atmos. Terr. Phys., 30, 795-823, 1968.

Igarashi, K., S. Kainuma, I. Nishimura, S. Okamoto, H. Kuroiwa, T. Tanaka, and T. Ogawa, Ionospheric and atmospheric disturbances around Japan caused by the eruption of Mount Pinatubo on 15 June 1991, J. Atmos. Terr. Phys., 56, 1227-1234, 1994.

Kanamori, H., J. Mori, and D. G. Harkrider, Excitation of atmospheric oscillations by volcanic eruptions, J. Geophys. Res., 99, 21,947-21,961, 1994.

Kirchengast, G., Elucidation of the physics of the gravity wave-TID relationship with the aid of theoretical simulations, J. Geophys. Res., 101, 13353-13368, 1996.

Lay, T., H. Kanamori, C. J. Ammon, M. Nettles, S. N. Ward, R. C. Aster, S. L. Beck, S. L. Bilek, M. R. Brudzinski, R. Butler, H. R. DeShon, G. Ekström, K. Satake, and S. Sipkin, The great Sumatra-Andaman earthquake of 26 December 2004, Science, 308, 1127-1133, 2005.

Ogawa, T., H. Kumagai, and K. Sinno, Ionospheric disturbances over Japan due to the 18 May 1980 eruption of Mount St. Helens, J. Atmos. Terr. Phys., 44, 863-868, 1982.

Olsen, N., T. J. Sabaka, and L. T. Clausen, Determination of the IGRF 2000 model, Earth Planet Space, 52, 1175-1182, 2000.

Park, J., K. Anderson, R. Aster, R. Butler, T. Lay, and D. Simpson, Global seismographic network records the great Sumatra-Andaman earthquake, EOS, 86, 57, 2005.

Picone, J. M., A. E. Hedin, D. P. Drob, and A. C. Aikin, NRLMSISE-00 empirical model of the atmosphere: Statistical comparisons and scientific issues, J. Geophys. Res., 107(A12), 1468, doi:10.1029/2002JA009430, 2002.

Saito, A., S. Fukao, S. Miyazaki, High resolution mapping of TEC perturbations with the GSI GPS network over Japan, Geophys. Res. Lett., 25, 3079-3082, 1998.

Tanaka, T., T. Ichinose, T. Okuzawa, T. Shibata, Y. Sato, C. Nagasawa, and T. Ogawa, HF-Doppler observations of acoustic waves excited by the Urakawa-oki earthquake on 21 March 1982, J. Atmos. Terr. Phys., 46, 233-245, 1984.

Y. Otsuka (e-mail: otsuka@stelab.nagoya-u.ac.jp), N. Kotake, T. Tsugawa, K. Shiokawa, T. Ogawa, Effendy, S. Saito, M. Kawamura, T. Maruyama, N. Hemmakorn, and T. Komolmis 